\title{
DESIGN OF MANUFACTURING SIMULATIONS OF A FLATPLATE PULSATING HEAT PIPE
}

\author{
Matteo Pontecorvo ${ }^{1}$ \\ ${ }^{1}$ School of Computing, Engineering and Mathematics \\ University of Brighton \\ Cockcroft building, Lewes Road, BN2 4GJ, Brighton, UK \\ M.Pontecorvo1@uni.Brighton.ac.uk
}

Keywords: Pulsating heat pipe, induced stress, titanium, sapphire, active soldering, bonding agent, static and thermal analyses

\begin{abstract}
Currently, a research team in the University of Brighton, in collaboration with the European Space Agency (ESA), is developing a pulsating heat pipe that will eventually be launched and tested in space, with the International Space Station (ISS) as destination, for research into passive thermal devices and their behaviour in a vacuum.
\end{abstract}

The approved pulsating heat pipe design incorporates one titanium plate, which is classified as a metal, and one aluminum-oxide sapphire plate that is classified as a ceramic. At the moment, the team is faced with the challenge of bonding the two plates together since, using convectional manufacturing methods, the parts fail due to the high level of induced stress. A research into manufacturing processes to bond together titanium and sapphire is essential to ensure that the final device will operate for several weeks (maybe even months) without leaking and the need for maintenance. The project explores potential manufacturing processes aimed to bond together these materials and subsequently propose a solution. Furthermore, static and thermal analyses are carried out with the aid of SolidWorks to exploit potential points of failure due to stress concentrations induced by cooling after bonding.

The results indicate that both titanium and sapphire are capable of sustaining the induced stresses but, due to the complex geometry of the pulsating heat pipe at the contact surface, the bonding agent is likely to fail due to the induced stresses.

\section{INTRODUCTION}

The prototype of the pulsating heat pipe is scheduled to be launched on the international space station in 2020 for research into passive thermal devices in microgravity. A pulsating heat pipe (PHP) is a passive thermal management system that works on the balance of the phases of the working fluid within it. The research on the device itself and its physics has been currently going on and the possible applications are numerous, such as in space technology and automotive industry [1]. It is known, however, that the device is very efficient in transporting heat [2]. The research team is currently facing the challenge of bonding the titanium and the sapphire plates together without either plate failing due to induced stress caused by current manufacturing techniques. Therefore, the main aim of the research was to develop a way of bonding these together in such a way that it will last over a long period of time under extreme condition (ISS-vacuum) and develop a model capable of gathering an insight into the way in which the materials will perform under manufacturing conditions. 
The project involved the exploration of existing manufacturing processes involving the bonding of metals and ceramics, in particular titanium and sapphire. These technologies were then applied pulsating heat pipes technology. Subsequently, the external stimuli induced by the manufacturing process has been simulated to exploit points that might fail due to induced stress, as well as the thermal load during standard operation. The design of the pulsating heat pipe used for the analyses was based on the design that the research team is currently using.

Moreover, it is necessary to mention that, to the best of the author's knowledge, a similar task has never been attempted before which implies a lack of literature on the subject and the proposed manufacturing technique and subsequent analyses are just an initial step towards the solution of the problem that is being currently researched.

\section{PULSATING HEAT PIPE}

\subsection{Flatplate pulsating heat pipe}

A pulsating heat pipe [2] is a very efficient passive thermal management system that works on a balance between phases and the motion of the working fluid induced by these changes in phase throughout the system. The design of the device can vary greatly depending on the desired characteristics and required outcome. For this study, a flatplate pulsating heat pipe will be studied. This device consists of two plates with the grooves embedded on each plate. The combination of titanium and sapphire were chosen mainly because of the similar coefficient of thermal expansion as it was predicted that the two plates would expand and contract similarly under the same thermal load. The device is usually divided into three main sections, as it can be seen in fig 1: the evaporator (heat is supplied to the system), the adiabatic section (no heat is supplied or rejected) and the condenser (heat is rejected from the system).

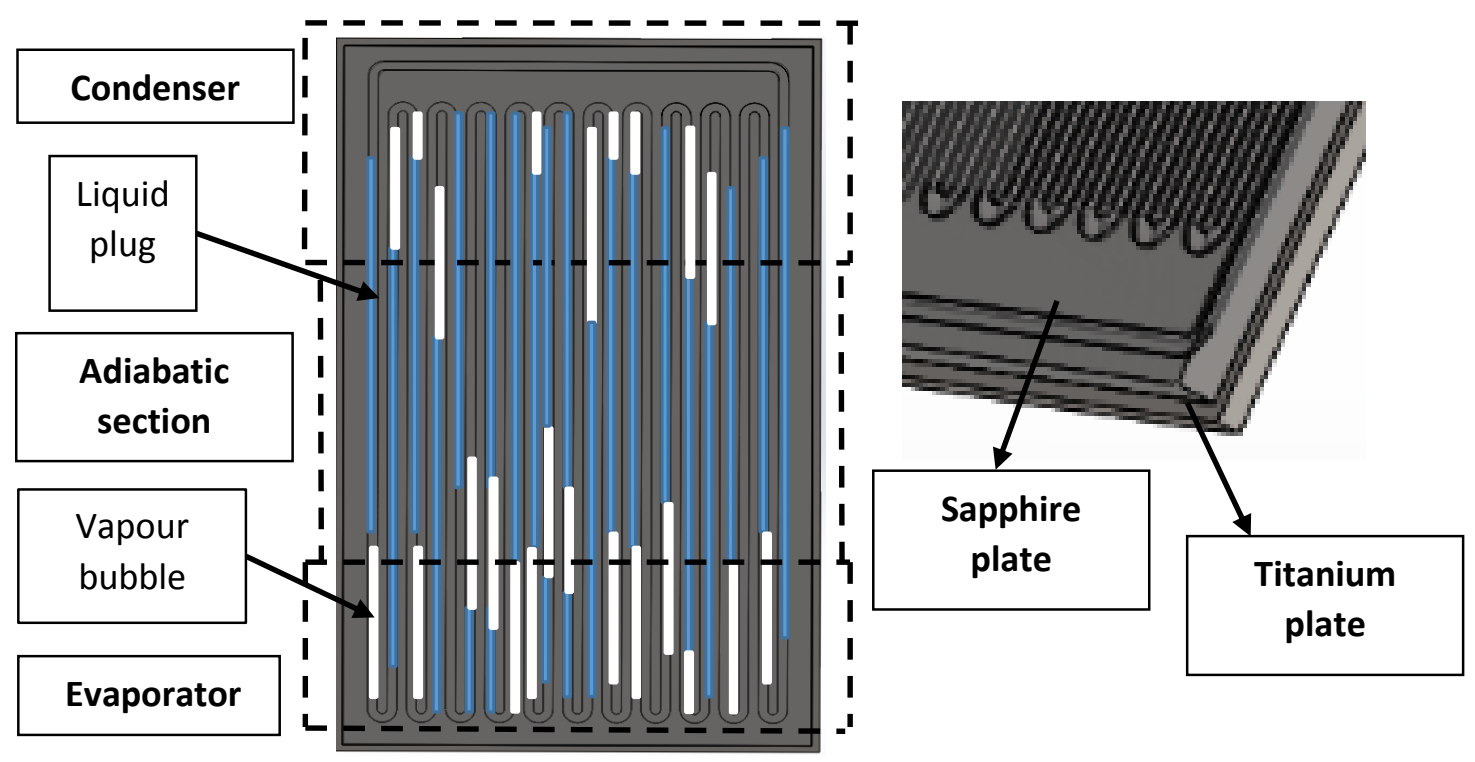

Figure 1: Flatplate pulsating heat pipe and enlargement of bottom right corner [1]

When heat is supplied to the system, the working fluid inside the pipe reaches its evaporating point and due to a combination of capillary forces, surface tension and shear forces the vapour rises, through the adiabatic section up to the condenser, where heat is rejected and the working fluid condenses and goes back to the evaporator via the adiabatic section. The cycle then repeats. 
There is no external work input or output and energy is transferred from the working fluid to the walls of the pipe due to frictional forces. Furthermore, the device doesn't need gravity assistance to fully function.

\subsection{Titanium plate}

Due to excellent mechanical properties, high corrosion resistance and thermal characteristics, titanium was chosen for this project [3]. Pure commercially available titanium (ti-55) was chosen for this application.

\subsection{Sapphire plate}

Sapphire [4] is chemically described as an aluminium-oxide $\left(\mathrm{Al}_{2} \mathrm{O}_{3}\right)$. It is classified as a ceramic and it possesses different properties depending on the purity of the material. One of the main advantages of this group of materials is the good thermal stability and mechanical strength at elevated temperatures. Sapphire was selected for this application because it allows the visualisation of the working fluid when in operation and the close observation of the boundaries thanks to infrared.

\section{MANUFACTURING TECHNIQUES}

Conventionally [5], in order to join two materials (similar or different), several processes can be used and these include welding, brazing, soldering and adhesive bonding. Welding was excluded mainly for the fact that it can only be applied to the same group of materials (metal - metal). Furthermore, some problems exist with the current conventional manufacturing process for bonding metals and ceramics to achieve the desired durability and applicability in vacuum. Oxidation is the main problem and it refers to the reaction of oxides present in the atmosphere (usually oxygen, carbon dioxide and/or water vapour) with the part being brazed and it can occur during any stage: preparation of the material, brazing and cooling. Other problems include distortion of the materials, fractures and requirements for surface preparation.

\subsection{Unconventional manufacturing processes}

\section{Active brazing}

Active brazing was considered but the temperature at which the process would take place is too high (approximately $450{ }^{\circ} \mathrm{C}$ ) as the induced stresses within the material would cause the parts to fail mechanically as proven by the research team at the university. No research was published on the matter as the research is internal to the university.

\section{Active soldering}

Active soldering involves the use of an active solder, which allows the direct bonding of ceramics (including sapphire) to metallic surfaces, promoting wettability of the surfaces and improving the conditions of the materials.

One of the main advantages of this process is that the flux (or solder) is not used and consequently all the problems related to the use of fluxes are eliminated [5]. Nevertheless, an active solder is used to create a small layer that will react (when agitated) with the ceramic and metallic surface. A very common element used as an active solder is titanium, but different variations can be used.

The joining surfaces are heated prior to bonding and subsequently the molten material is agitated via mechanical vibrations (that could be induced by rubbing or ultrasound). This motion prevents (or removes [6]) oxidation and the resulting joint possess good mechanical properties. The mechanical activation enables the wetting of both bonding surfaces. Nevertheless, the first two methods 
(scratching and vibrations) are mostly used to bond metal to metal, while ultrasound can be used to bond metallic surfaces to ceramics.

\section{ACTIVE SOLDERING APPLIED ON THE PULSATING HEAT PIPE}

Conventional manufacturing processes are not applicable for the production of a titanium - sapphire pulsating heat pipe because they can only join similar materials, therefore, only unconventional manufacturing processes are applicable. After the existing processes where compared based on set criteria (such as equipment required, preparation, costs, availability of equipment and more), it was concluded that active soldering with ultrasonic application (mechanical agitation method) was the most suitable process for this application. The list of parameters which were taken into account is presented in table 1.

\begin{tabular}{|c|c|c|c|c|c|c|c|c|c|}
\hline \multirow{2}{*}{ Parameters } & \multirow{2}{*}{\begin{tabular}{|c|} 
Vacuum furnace \\
Any \\
\end{tabular}} & \multirow{2}{*}{ Active brazing } & \multicolumn{4}{|c|}{ Active soldering } & \multirow{2}{*}{ Glass solder bonding } & \multirow{2}{*}{ Scale } & \multirow{2}{*}{ Importance } \\
\hline & & & Rubbing & Vibration & Ultrasound & Furnace & & & \\
\hline \multirow{2}{*}{ Equipment } & \multirow{2}{*}{1} & \multirow{2}{*}{6} & \multirow{2}{*}{8} & \multirow{2}{*}{8} & \multirow{2}{*}{8} & \multirow{2}{*}{1} & \multirow{2}{*}{5} & 1 - specilised & \multirow{2}{*}{7} \\
\hline & & & & & & & & 10 - Simple & \\
\hline \multirow{2}{*}{ Tools availability } & \multirow{2}{*}{1} & \multirow{2}{*}{7} & \multirow{2}{*}{7} & \multirow{2}{*}{7} & \multirow{2}{*}{7} & \multirow{2}{*}{1} & \multirow{2}{*}{8} & 1 -Impossible to obtain & \multirow{2}{*}{10} \\
\hline & & & & & & & & 10 - available straightaway & \\
\hline \multirow{2}{*}{ Investment } & \multirow{2}{*}{1} & \multirow{2}{*}{6} & \multirow{2}{*}{7} & \multirow{2}{*}{7} & \multirow{2}{*}{7} & \multirow{2}{*}{1} & 7 & 1 - High & 6 \\
\hline & & & & & & & & 10 - low & 6 \\
\hline Skiils & 1 & 7 & 8 & 8 & 8 & 1 & 10 & 1-Specilised & 7 \\
\hline JKIIIS & 1 & ${ }^{\prime}$ & 8 & 8 & 8 & 1 & 10 & $10-$ no skills required & 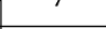 \\
\hline Training & 1 & 7 & 7 & 7 & 7 & 1 & 10 & 1 -Specilised & 5 \\
\hline & & & & & & & & 10 - no training requiered & \\
\hline Time & 2 & 7 & 6 & 6 & 7 & 2 & 10 & 1 - longer than the project & 9 \\
\hline ffoti: & 10 & 0 & 0 & 0 & 0 & 10 & & 1 - doesn't work & 10 \\
\hline effectiveness & 10 & 8 & 8 & 9 & 9 & 10 & 4 & 10 - works perfectly & 10 \\
\hline Complexity & 5 & 7 & 8 & 6 & 8 & 5 & 9 & 1 - hihgly complex & 8 \\
\hline Complexity & 3 & I & 8 & 0 & 8 & 3 & 9 & 10 - simple & 8 \\
\hline Vacuum tightness & 9 & 7 & 8 & 8 & 8 & 9 & 4 & 1- doesn't work & 10 \\
\hline Vacuum tigntness & $y$ & 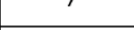 & & 8 & 8 & 9 & 4 & 10 - completely tight & 10 \\
\hline Physical properties & 8 & 9 & 8 & 8 & 9 & 8 & 5 & 1 - weakest possible & 10 \\
\hline & & & & & & & & 10 - strongest & \\
\hline Limitation & 3 & 6 & 6 & 6 & 6 & 3 & 4 & 1 - many & 6 \\
\hline & & & & & & & 4 & 10 - no limitations & \\
\hline Final score & 382 & 604 & 630 & 624 & 659 & 382 & 558 & Highest score & \\
\hline
\end{tabular}

Table 1 -Decision matrix for manufacturing process selection [4] [10]

\subsubsection{Mechanically induced chemical modifications}

Wetting is a key element in making sure that the active solder spreads uniformly and effectively onto the surface of the bonding materials. One of the main factor affecting this phenomenon is the chemistry of the surface, which can be actively modified by surface treatment (that varies depending on the material involved). The working mechanism behind this process is the way in which the polymer chains are split as a result of stresses induced by local cavitation. According to Caruso et al. [7], mechanical induced activation can be achieved by "inducing macroscopic loads to the bulk polymer to cause selective chemical transformations at atomic level". Therefore, it can be hypothesised that the process would work better if the induced agitation is localised in specific points. 


\subsubsection{Procedures for hypothetical manufacturing process}

This hypothetical manufacturing process was developed based on previous research conducted Koleňák and Kostolny [8] under similar circumstances with similar materials. Sapphire was tested several times (in combination with a different metal plate) and good mechanical strength was recorded for the newly formed joint. The manufacturing process has the following steps, similar to the research mentioned [7] are presented in the flow chart 1:

- Both sapphire and titanium are placed on a hot plate.
- The hot plate is turned on and the desired soldering temperature is reached.
The temperature will be $250^{\circ} \mathrm{C}$ as per active solder's datasheet (S-bond
technology [9]) provided by the supplier.
- The bonding agent is positioned on the sapphire surface once it has been
brought to the soldering temperature.
the bonding
- The agent is then activated via ultrasound activation (in specific contacts
points) for a few seconds (5s). The excessive bonding agent is then removed
from the surface via brushing.
Joining of parts
and cooling

Flow chart 1 - Active soldering method

The numerical simulation was carried out after this alternative manufacturing process was proposed.

\section{FINITE ELEMENT ANALYSIS MODEL, SETTINGS AND OPERATING CONDITION}

Finite Element analysis will be performed with Solidworks on the final assembly of the PHP to research where stress concentrations occur when subjected to a temperature gradient. The part is mainly divided into two components. A sapphire plate and a titanium plate.

\subsection{Assumptions for the simulations}

The geometry used is the same and it hasn't been varied in any of the analysis that were carried out. To the best of the author's knowledge a similar task was never carried out before and consequently many assumptions were taken to attempt to simulate the simplest scenario [10]. The followings are the assumptions:

1. The heating of each component has already taken place.

2. The active solder has been applied uniformly over the surface of each part.

3. The active solder has no thickness $(0 \mathrm{~mm})$.

4. The expansion of the individual parts is negligible.

5. The two parts are perfectly paired together.

6. No-slip condition between the mating surfaces of each component.

7. The materials selected display similar coefficient of thermal expansion compared to the actual materials (PHP).

8. For the operating condition, the fluid is assumed to be adiabatic.

9. The effect of thermal radiation from the plates is assumed to be negligible. 


\subsection{Main parameters of the simulations}

An overview of the mesh on both plates can be seen in Figure 2 .

Table 2: Parameters of the simulations

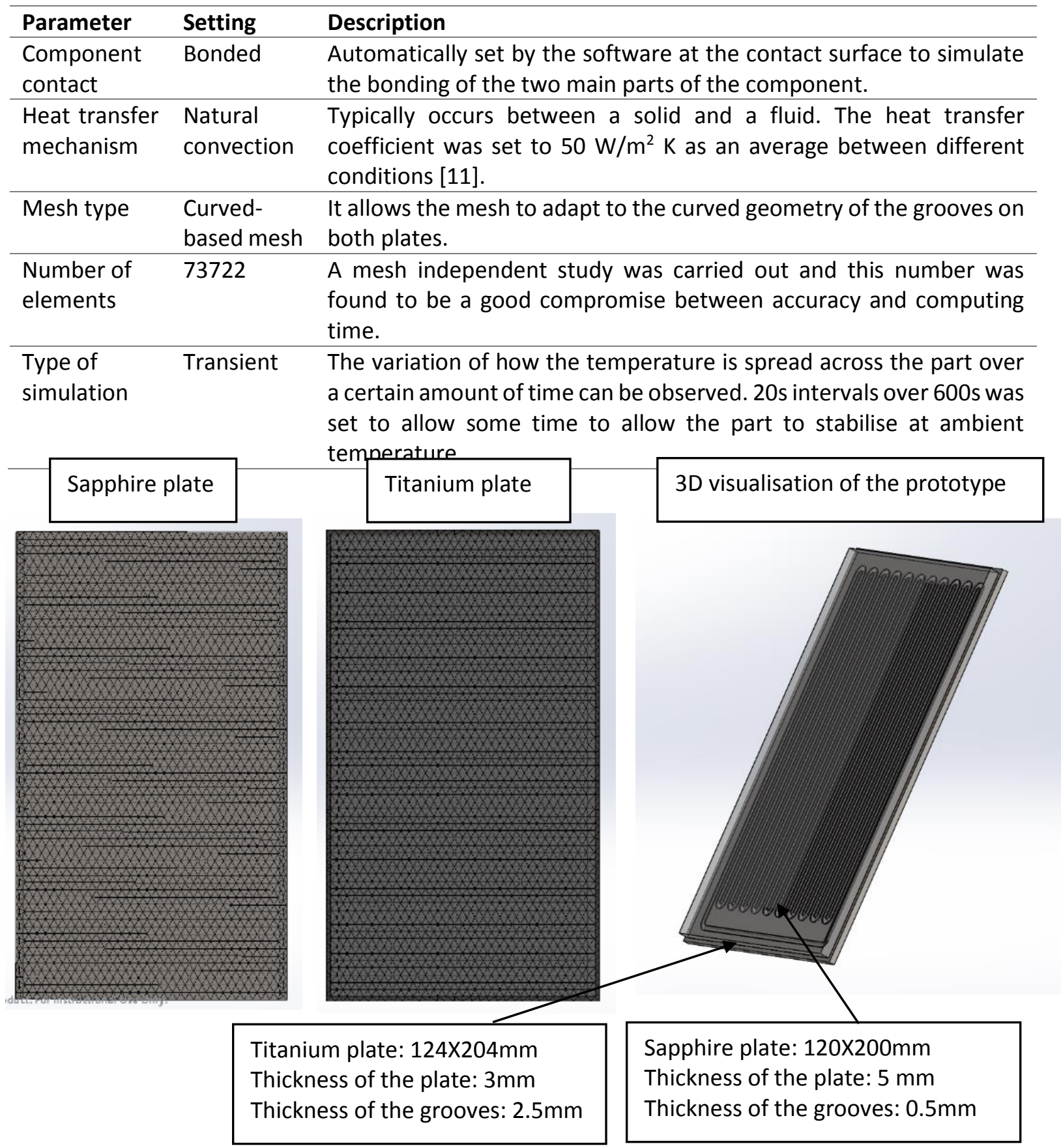

Figure 2 - Mesh settings of both plates and 3D visualisation of the pulsating heat pipe prototype 


\subsection{Material properties}

The most important mechanic and thermal properties of the two tested materials are summarised in table 3 (the data was taken from the software database and a technical sheet provide by the research team):

\begin{tabular}{llccc}
\hline & & Titanium & Sapphire & Bonding agent \\
\hline Property & Unit & & Value & \\
\hline Elastic modulus & $\mathrm{GPa}$ & 105 & 400 & $\mathrm{~N} / \mathrm{A}$ \\
\hline Poisson's ratio & & 0.37 & 0.29 & $\mathrm{~N} / \mathrm{A}$ \\
\hline Shear modulus & $\mathrm{GPa}$ & 39 & 175 & $\mathrm{~N} / \mathrm{A}$ \\
\hline Yield strength & $\mathrm{Pa}$ & 377 & $\mathrm{~N} / \mathrm{A}$ & $\mathrm{N} / \mathrm{A}$ \\
\hline Mass density & $\mathrm{Kg} / \mathrm{m}^{3}$ & 4500 & 3897 & $\mathrm{~N} / \mathrm{A}$ \\
\hline Young's Modulus & $\mathrm{GPa}$ & 105 & 400 & $\mathrm{~N} / \mathrm{A}$ \\
\hline Compressive strength & $\mathrm{GPa}$ & $\mathrm{N} / \mathrm{A}$ & 2.0 & $\mathrm{~N} / \mathrm{A}$ \\
\hline Thermal exp Coeff. & $\mathrm{1} / \mathrm{K}$ & 0.000009 & 0.000009 & $\mathrm{~N} / \mathrm{A}$ \\
\hline Thermal conductivity & $\mathrm{W} /(\mathrm{m} \mathrm{k})$ & 18 & 40 & $\mathrm{~N} / \mathrm{A}$ \\
\hline Specific heat & $\mathrm{J} /(\mathrm{Kg} \mathrm{K})$ & 540 & 750 & $\mathrm{~N} / \mathrm{A}$ \\
\hline Ultimate tensile strength & $\mathrm{MPa}$ & 344 & 300 & 24-35
\end{tabular}

Table 3: Mechanical and thermal properties of materials and bonding agent

\subsection{Operating condition}

Standard method (from cold to warm): the initial temperature of the pipe was set room temperature $\left(20^{\circ} \mathrm{C}\right)$, the evaporator part was heated up to a $100^{\circ} \mathrm{C}$ and the induced stress due to thermal loading was observed. Consequently, the part is assumed to be already assembled and bonded together.

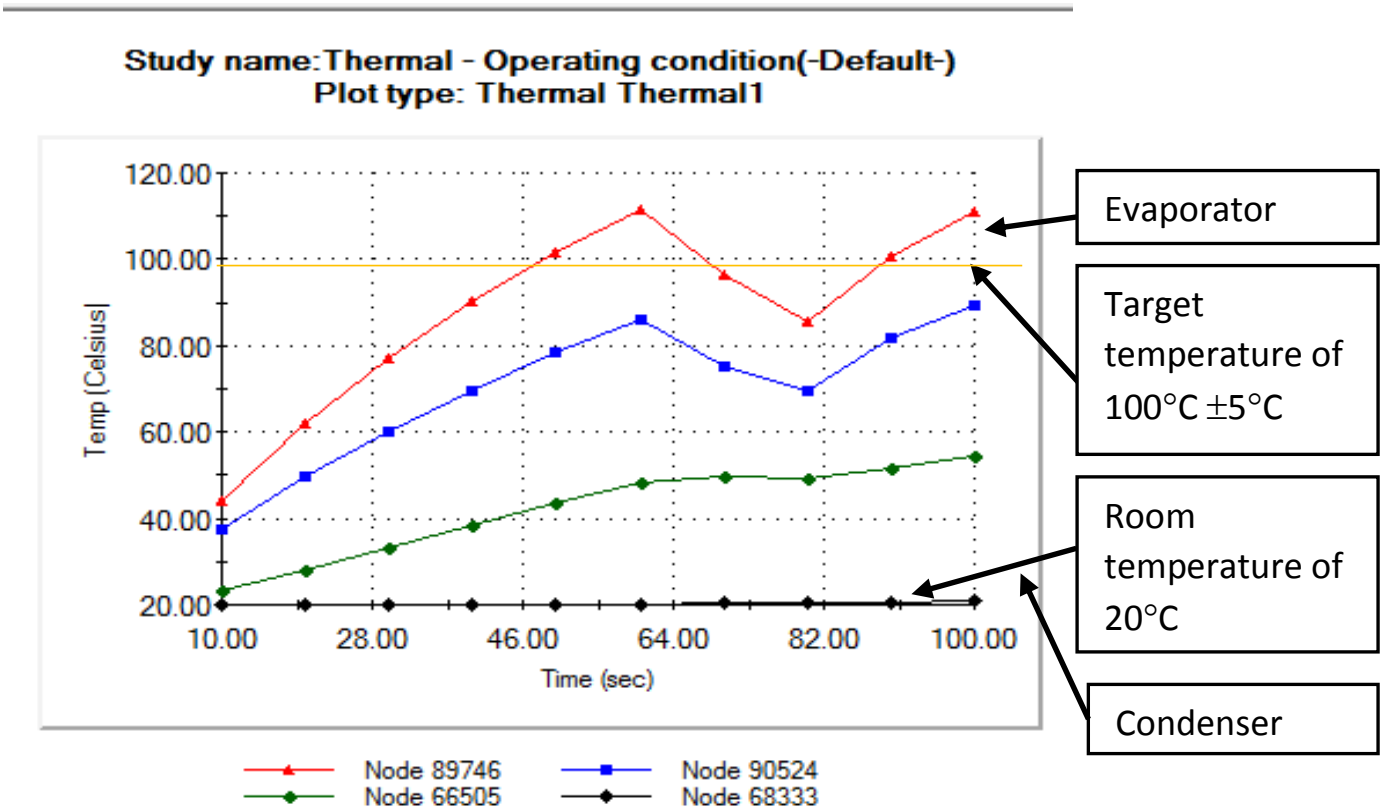

Figure 3: Thermal analysis for operating condition [graph generated by SolidWorks]

Four different points were taken, one at the evaporator, one at the condenser and two between to verify the variation of temperatures at these points as shown in figure 3 . 
6 RESULTS OF THE FINITE ELEMENT ANALYSIS

\begin{tabular}{|c|c|c|c|c|}
\hline Category & Parameter & Unit & Manufacturing & Operation \\
\hline Stress & Von Mises & $\mathrm{MPa}$ & 38.10 & 35.90 \\
\hline Strain & Induced strain & & $1.8 \mathrm{E}-4$ & $6.09 \mathrm{E}-5$ \\
\hline Displacement & Displacement & $\mathrm{mm}$ & 0.05580 & 0.0261 \\
\hline \multirow{4}{*}{$\begin{array}{l}\text { Simulation } \\
\text { settings }\end{array}$} & Mesh nodes & $n^{\circ}$ & 154003 & 169909 \\
\hline & Mesh elements & $n^{\circ}$ & 94618 & 102621 \\
\hline & Time of simulation & \multirow[b]{2}{*}{$\mathrm{s}$} & 600 & 100 \\
\hline & Step increase & & 20 & 10 \\
\hline \multirow{4}{*}{ Safety factors } & Titanium plate & & 13.49 & 9.58 \\
\hline & Sapphire plate & & 7.87 & 8.36 \\
\hline & Bonding agent_lower limit & & 0.94 & 0.67 \\
\hline & Bonding agent_upper limit & & 1.37 & 0.97 \\
\hline
\end{tabular}

Table 4: Numerical results of the simulations

The results (shown in table 4) indicate that, with the proposed manufacturing solution, the stress induced within the two plates (titanium and sapphire) is below the safety limit of the materials and consequently both plates are capable of sustaining the stress induced due to shrinking. On the other hand, the stress induced between the two plates (at the contact surface) is at its maximum tolerance and it can be concluded that the bonding agent is likely to fail due to the lower mechanical strength compared to the materials.

According to the simulations, the results for the operating condition are similar to the results obtained for the manufacturing condition. Both titanium and sapphire plate are capable of sustaining the induced stress whilst the bonding agent is very likely to fail.

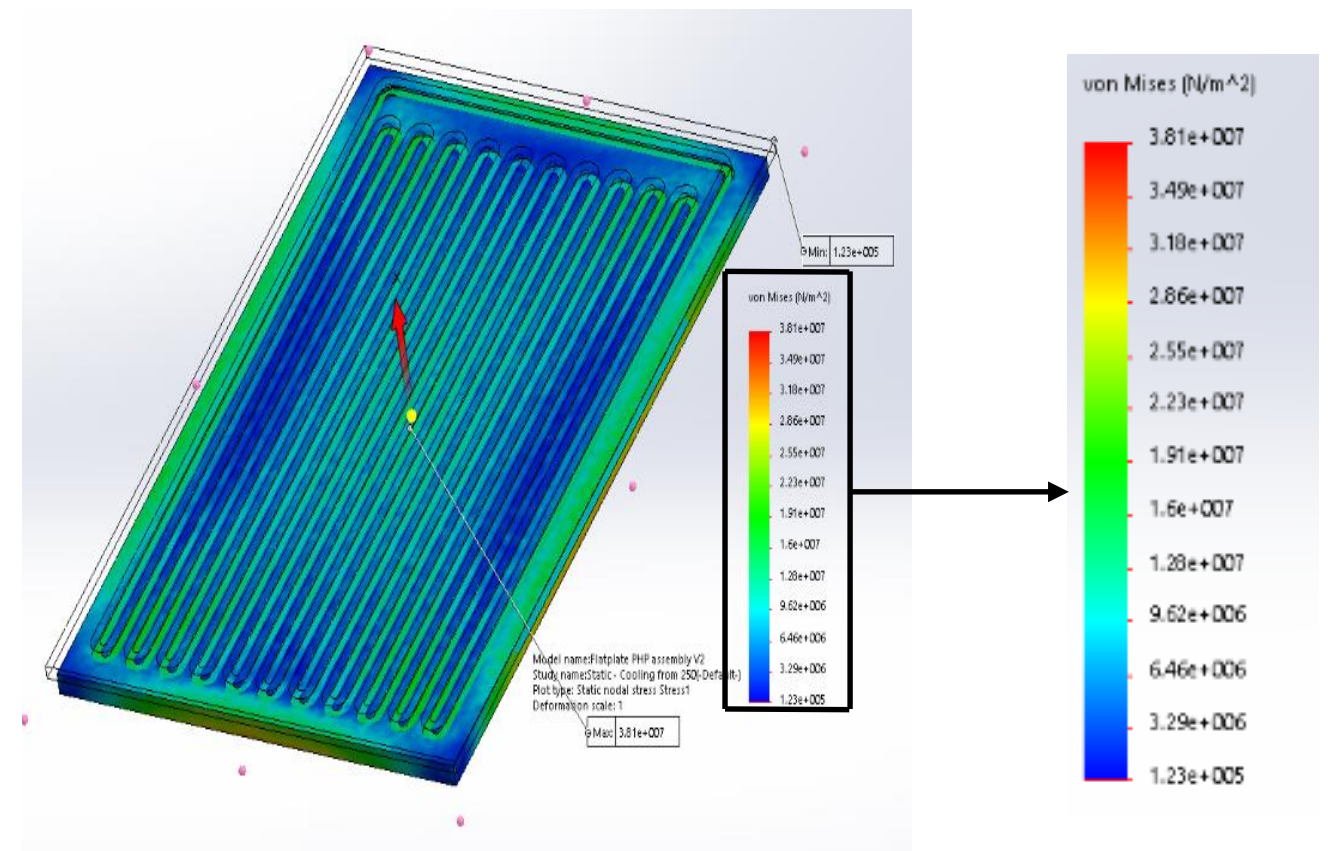

Figure 4: Stress computed by SolidWorks across contact surface at manufacturing condition and enlargement of results 


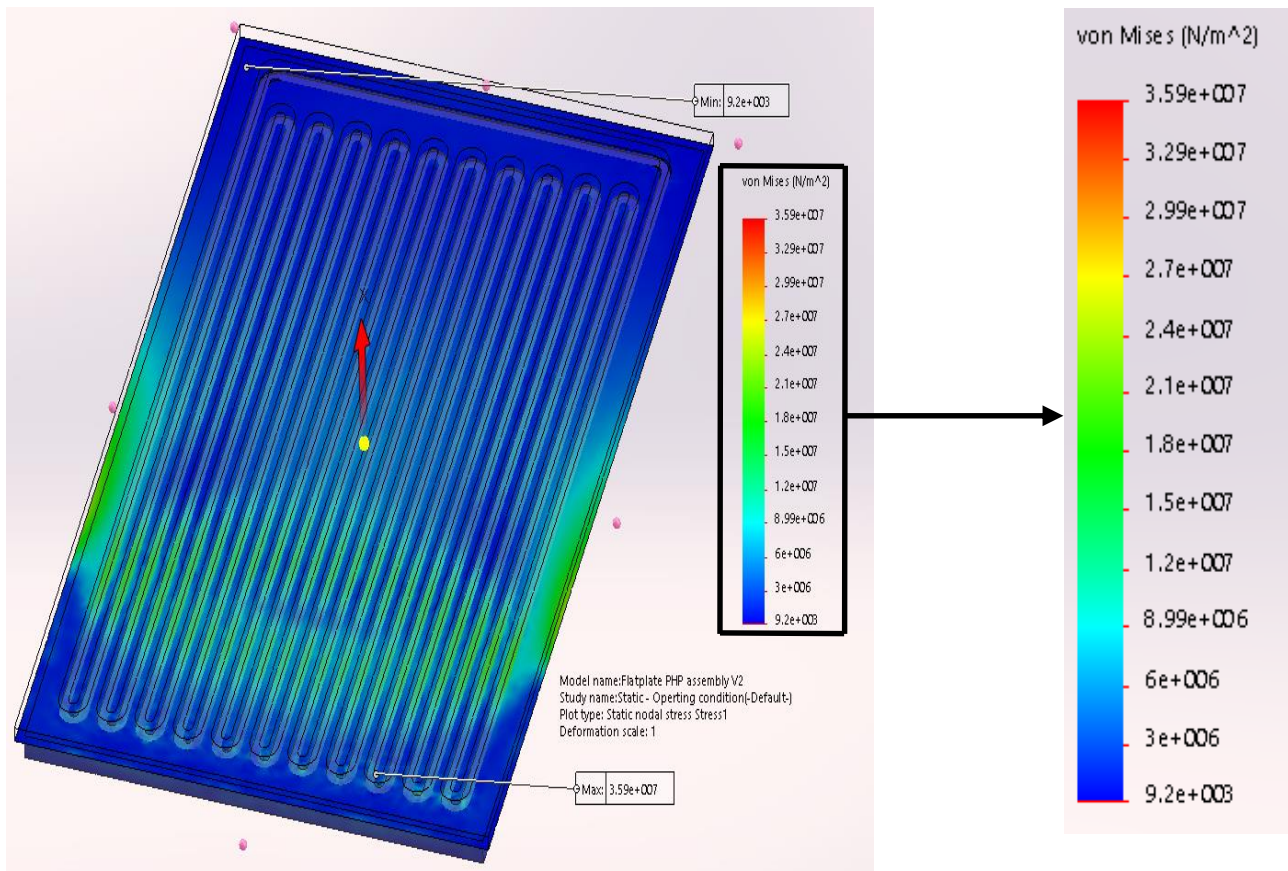

Figure 5: Stress computed by SolidWorks across contact surface at operating condition and enlargement of results

\subsection{Results of the simulation under manufacturing conditions}

\begin{tabular}{cl}
\hline $\begin{array}{c}\text { Base of the } \\
\text { sapphire plate }\end{array}$ & $\begin{array}{l}\text { The stress is relatively higher on the sides of this plate than the titanium plate as it } \\
\text { appears to reach the maximum value recorded of } 38.1 \mathrm{MPa} \text { at the far ends of the } \\
\text { base. The stress is likely to accumulate on the sides of the plate as there is an abrupt } \\
\text { change in the geometric features in those points. }\end{array}$ \\
$\begin{array}{c}\text { mid-plate of } \\
\text { the sapphire } \\
\text { plate }\end{array}$ & $\begin{array}{l}\text { Measuring the stress in terms of the ultimate tensile strength of 300MPa, the } \\
\text { induced stress remains relatively low (between the minimum value of } 123 \mathrm{kPa} \text { and } \\
25.5 \mathrm{MPa} \text { ) throughout the plate, with higher stresses on the sides and within the } \\
\text { grooves and lower stresses in the corners. }\end{array}$ \\
\hline $\begin{array}{c}\text { Contact } \\
\text { surface }\end{array}$ & $\begin{array}{l}\text { The stress is relatively spread across the surface, with a higher concentration on the } \\
\text { sides. The stress recorded is between } 123 \mathrm{kPa} \text { and approximately } 25.5 \mathrm{MPa} \text {. The } \\
\text { induced tensile stress by the shrinking of the part propagates at an angle of } 45^{\circ} \text { with } \\
\text { respect to the applied force (stress transformation [12]). }\end{array}$ \\
\hline $\begin{array}{c}\text { mid-plate of } \\
\text { the titanium } \\
\text { plate }\end{array}$ & $\begin{array}{l}\text { The induced stress is approximately between } 12.8 \mathrm{MPa} \text { and } 25.5 \mathrm{MPa} \text {. Furthermore, } \\
\text { on the sides of the plate the stress seem to be relatively lower compared to the } \\
\text { stress experienced within the grooves (About } 9.62 \mathrm{MPa} \text { ). }\end{array}$ \\
\hline Top of the & $\begin{array}{l}\text { The stress seems to be concentrated across the grooves where the turns are and on } \\
\text { the sides of the plate. The level of stress on the } 4 \text { sides of the plate, as well as the } \\
\text { titanium plate }\end{array}$ \\
\hline
\end{tabular}

Table 5: Summary of results at manufacturing condition 


\subsection{Results of the simulation under operating condition}

\begin{tabular}{cl}
$\begin{array}{c}\text { Base of the } \\
\text { sapphire plate }\end{array}$ & $\begin{array}{l}\text { The bottom of the sapphire plate is nearly unaffected. The highest stress is } \\
\text { recorder on the left and right side of the plate (around } 24 \mathrm{MPa} \text { ) and slightly lower } \\
\text { within the plate (approximately 8.99 MPa). The stress goes across the plate from } \\
\text { the left side to the right side (or vice versa). }\end{array}$ \\
\hline $\begin{array}{c}\text { mid-plate of the } \\
\text { sapphire plate }\end{array}$ & $\begin{array}{l}\text { The patter of the induced stress is the same as for the bottom of the plate. The } \\
\text { level of the stress induced is roughly the same. }\end{array}$ \\
\hline Contact surface & $\begin{array}{l}\text { The level of stress experienced between the plates (contact surface) follows the } \\
\text { same patter and the intensity recorded is also the same as for the other planes. }\end{array}$ \\
\hline $\begin{array}{c}\text { mid-plate of the } \\
\text { titanium plate }\end{array}$ & $\begin{array}{l}\text { The level of stress is experienced in the same points as for the sapphire plate (on } \\
\text { the left and right side) with similar intensity. Furthermore, similar levels of stress } \\
\text { are experienced within the grooves (between 12 MPa to 24 MPa). }\end{array}$ \\
\hline $\begin{array}{c}\text { Top of the } \\
\text { titanium plate }\end{array}$ & $\begin{array}{l}\text { The induced stress intensity and the location is the same as for the planes } \\
\text { previously analysed. }\end{array}$
\end{tabular}

Table 6: Summary of results at operating condition

A visual representation of the pulsating heat pipe under both manufacturing and operating condition is shown in figure 4 (manufacturing condition) and 5 (operating condition).

\section{CONCLUSION AND FUTURE RESEARCH}

The research indicates that the materials selected for the prototype of the pulsating heat pipe can sustain the induced stress during manufacturing as the maximum stress recorded was $25.50 \mathrm{Mpa}$ and 38.10MPa for titanium and sapphire respectively. Moreover, under operating condition the maximum stress recorded was $35.90 \mathrm{MPa}$. This is an improvement on the previous manufacturing methods proposed where the plates would fail because of the high level of stress induced as mentioned in section 3.1. On the other hand, it was discovered that the part is likely to fail at the contact surface because the stress recorded in that location exceeds the ultimate tensile strength of the bonding agent, as mentioned in table 3 . Therefore, in order to solve the bonding between the two parts, the geometric features of the plates could be altered to promote lower level of stress in the part. This solution, however, requires a major change in design and therefore was not pursued in this paper. Currently there is research ongoing based on the proposed manufacturing process as well as techniques to reduce stress concentrations in specific points.

\section{ACKNOWLEDGEMENT}

Many thanks to my supervisor, Dr Nicolas Miché for the opportunity of joining the current research involving pulsating heat pipes and for the constant support throughout the project and Dr Agnieszka Kwiek for the support during the preparation of this paper. Furthermore, I would like to thank the University of Brighton, as well as Professor Marco Marengo, in collaboration with ESA, for the financial and technical support offered. 


\section{REFERENCES}

[1] Bastakoti, D., Zhang, H., Li, D., Cai, W. AND Li, F. An overview on the developing trend of pulsating heat pipe and its performance. Applied Thermal Engineering, 141, pp.305-332.

[2] Ma, H. (2016). Oscillating heat pipes. Springer-Verlag. New York.

[3] Leyens, C. and Peters, M. (2006). Titanium and Titanium Alloys. Hoboken: Wiley.

[4] Pishchik, V., Dobrovinskaya, E. R. and Lytvynov, L. A. (2009). Sapphire: material, manufacturing, applications. Springer Science \& Business Media.

[5] Groover, M. P. (2010). Fundamentals of modern manufacturing Groover. Hoboken, NJ: J. Wiley \& Sons.

[6] Chang, S. Y., Lu, M. H., Tsao, L. C. and Chuang, T. H. (2006). Active Soldering of ITO to Copper.

[7] Caruso, M. M., Davis, D. A., Shen, Q., Odom, S. A., Sottos, N. R., White, S. R. and Moore, J. S. (2009). Mechanically-Induced Chemical Changes in Polymeric Materials. Chemical Reviews, 109(11), pp.5755-5798.

[8] Koleňák, R. and Kostolný, I. (2015). Study of Direct Bonding Ceramics with Metal Using Sn2La Solder. Advances in Materials Science and Engineering, pp.1-13.

[9] S-Bond Technologies - Ceramic to Metal Bonding. (2013). S-Bond Technologies 1st ed. $811 \mathrm{~W}$. Fifth Street, Lansdale, PA 19446, USA: S-Bond Technologies.

[10] Cengel, Y. A. (2007). Heat transfer, A practical approach. 2nd ed. Boston: McGraw-Hill.

[11] Convective heat transfer coefficients table chart. Engineersedge.com. (2018). [online] Available at: https://www.engineersedge.com/heat_transfer/convective_heat_transfer_coefficients_13378. htm

[12] Gere, J. M. (2004) Mechanics of materials 6th ed. Thomson Learning, Inc.

\section{COPYRIGHT STATEMENT}

The authors confirm that they, and/or their company or organization, hold copyright on all of the original material included in this paper. The authors also confirm that they have obtained permission, from the copyright holder of any third party material included in this paper, to publish it as part of their paper. The authors confirm that they give permission, or have obtained permission from the copyright holder of this paper, for the publication and distribution of this paper as part of the READ 2018 proceedings.

This is an open access article distributed under the Creative Commons Attribution License which permits unrestricted use, distribution, and reproduction in any medium, provided the original work is properly cited. (CC BY 4.0). 